\title{
The Psychiatry Ashes Test update
}

In the first month of play, the teams from BJPsych and ANZJP have made a strong start. See http://bit.ly/2GOfUaJ for further details of the competition, including the full rules.

\begin{tabular}{|c|c|c|c|c|c|}
\hline \multicolumn{3}{|l|}{ BJPsych } & \multicolumn{3}{|l|}{ ANZJP } \\
\hline Player & Stroke power & January cumulative run score & Player & Stroke power & January cumulative run score \\
\hline K Bhui (captain) & 33 & 33 & G Malhi (captain) & 55 & 81 \\
\hline S Wessely & 26 & 30 & G Parker & 14 & 14 \\
\hline G Lewis & 24 & 24 & P McGorry & 44 & 54 \\
\hline P Buijpers & 71 & 73 & M Berk & 37 & 80 \\
\hline A Young & 39 & 39 & N Martin & 42 & 68 \\
\hline M Hotopf & 51 & 53 & R Bryant & 37 & 46 \\
\hline M King & 48 & 50 & A Jorm & 39 & 39 \\
\hline E Simonoff & 6 & 6 & W Hall & 60 & 66 \\
\hline F O’Neill & 23 & 61 & J Kulkarni & 19 & 22 \\
\hline N Kapur & 20 & 20 & P Fitzgerald & 11 & 28 \\
\hline L Howard & 24 & 24 & J Scott & 48 & 125 \\
\hline Total & 365 & 413 & Total & 406 & 623 \\
\hline
\end{tabular}

